\title{
Copula - Based Bivariate Drought Severity and Duration Frequency Analysis Considering Spatial- Temporal Variability in the Ceyhan Basin, Turkey
}

Musa Esit ( $\square$ mesit@adiyaman.edu.tr)

Adiyaman University: Adiyaman Universitesi https://orcid.org/0000-0003-4509-7283

Mehmet Ishak YUCE

Gaziantep University

\section{Research Article}

Keywords: Drought, Copula, Bivariate distribution, SPI, Return period, Ceyhan basin, Turkey

Posted Date: January 18th, 2022

DOI: https://doi.org/10.21203/rs.3.rs-1239394/v1

License: (c) (i) This work is licensed under a Creative Commons Attribution 4.0 International License.

Read Full License 


\section{Abstract}

In recent times, copula families have been mostly employed in bivariate drought duration and severity. Archimedean copulas are mainly used conveniently among various potential families for hydrologic design and water resource management. In this study, drought events are defined by standard precipitation index (SPI 1-, 3- and 6-time series) series for 24-gauge stations in Ceyhan Basin Turkey, when the value fell below zero. Both duration and severity are tested their dependence with Mann-Kendall and Spearman Rho trend test at 0.05 significant level. The different marginal distribution function is fitted to duration and severity data. Weibull and Lognormal distribution for drought duration, Weibull and Gamma distribution for drought severity are found more appropriate, respectively. The best fit copula is found to construct a joint distribution function. However, disregarding tail dependencies can cause high uncertainty in extreme quantile predictions, resulting in incorrect hydrological design findings. Hence, the influence of upper tail dependencies is tested to select the most appropriate copula function. After acquiring the best fit copula, the joint return periods are modeled for each station. Finally, considering drought risk categories (light, moderate, severe and extreme drought), spatial distributions of drought riskreturn period are constructed. Apart from using univariate frequency analysis, bivariate frequency analysis is performed to model the joint return period based on copula theory that is great of importance for hydrology design and water resource management.

\section{Introduction}

Drought is regarded as a complex natural reoccurring phenomenon, which may affect many areas of the world, resulting in a precipitation deficit compared with the expected or normal amount over some period (Mckee et al. 1993; Chen and Sun 2015; Esit et al. 2021). Unlike many natural disasters that occur sudden, droughts are an insidious and can produce tremendous negative impact environmental (Mirabbasi et al. 2012; Sheffield et al. 2012), agricultural (Wang et al. 2019a) and socio-economic damage (Chen et al. 2013; Tosunoglu and Can 2016). For instance, in global damages, droughts may annually cause as economic losses about $\$ 6-\$ 8$ billion (Wilhite 2000) and collectively affected a large population (including $35 \%$ of those affected by natural disasters) than other climate-related natural disasters (She and Xia 2018).

Comprehensive drought definition has been provided by researchers (Linsley et al. 1949; GUMBEL 1963; Palmer 1965; Yevjevich 1966; Wilhite and Glantz 1985; Organization (WMO) and World Meteorological Organization (WMO) 1986; Mishra and Singh 2009; Schneider 2011) due to complexity of causes and influencing factors of drought. Drought may generally be classified into four categories, i.e., meteorological, hydrological, agricultural, and socio-economic drought (Mishra and Singh 2010). In drought analysis, a variety of indices have been developed to assess and monitor droughts. The Standardized Precipitation Index (SPI) (Mckee et al. 1993) and Palmer Drought Severity Index (PDSI) are widely used methods for drought characterization. PDSI, based on water balance accounting using precipitation and temperature parameters, is generally used within the United States. PDSI has little acceptance by many researchers due to several limitations (suspicion of water balance model, temporal 
scale, PDSI value) (Kao and Govindaraju 2010). Unlike PDSI, SPI, which considers the deficiency of precipitation, is based on the probability concept to classify the drier and wetter climates (Cancelliere et al. 2007). Owing to its simplicity for calculating multiple time scales, SPI is widely accepted all the world using precipitation parameters (Guttman 1998) solely.

Drought characteristics are usually analyzed separately by univariate frequency analysis (Cancelliere and Salas 2004; Serinaldi et al. 2009). Because of complexity phenomena, using one parameter cannot depict the extensive impact of drought events. Two significant randomly correlated drought characteristics are generally used in literature as severity and duration (Shiau and Modarres 2009; Shiau et al. 2012). For investigating the impact of drought, a convenient method is to employ the stochastic process and the probability theory method (Shiau 2006; Tosunoglu and Kisi 2016). However, since drought variables (e.g. severity and duration) are randomly correlated to each other, univariate analysis of drought characteristics cannot provide a significant correlation between these variables. Multivariate analysis characteristic is a better approach for assessing drought characteristics. But, multivariate models are complicated to derive joint distribution functions of drought variables (Mishra and Singh 2010). For instance, Bonaccorso et al., Kim et al., Salas et al., and Shiau \& Shen (Shiau and Shen 2001; Bonaccorso et al. 2003; Kim et al. 2003; Salas et al. 2005) have suggested the different theories for identifying the joint distribution of drought variables. However, due to some difficulty mathematical derivations and obtaining their parameters by fitting the observed data, these models are not applicable (Chen et al. 2013).

Bivariate and multivariate distributions using copula functions may overcome the above-stated problems. The copula is an effective method to assess the dependency and correlation among multiple variables by linking multivariate distribution depending on their univariate marginal distribution (SKLAR 1959). In recent years, copulas are widely used as a method for addressing multivariate hydrological analysis problems. For example, copulas have been employed for flood frequency analysis (Zhang and Singh 2006; Shiau 2006; Wang 2016; Alamgir et al. 2018; Durocher et al. 2018; Dong et al. 2019), rainfall frequency analysis (Zhang and Singh 2006; Kuhn et al. 2007; Kao and Govindaraju 2010), drought frequency analysis (Masud et al. 2015; Kwon and Lall 2016; Vazifehkhah et al. 2019; Wang et al. 2019b; Hui-Mean et al. 2019), for predicting groundwater parameters (Bárdossy 2006) and for estimating streamflow discharge using remote sensing (Chacon-Hurtado et al. 2017). A comprehensive description of theoretical backgrounds for using copulas can be found in Salvadori et al. (2007) and Nelsen (2007).

For bivariate drought frequency analysis, Shiau (2006) and Shiau et al. (2007) constructed joint probabilities and return periods for drought severity and duration using two-dimensional copulas. Yoo et al. (2016) modeled confidence intervals of bivariate drought frequency curve after analyzing the model performance of several copula functions. Applying the Copula-GARCH rainfall generation model, 100 realizations of 100-year long monthly precipitation were produced. Ahmadi et al. (2018) applied copula for estimating bivariate frequency analysis of low flow in Dez River Basin, Iran. Song and Singh (2010a) constructed the joint probability distribution of more than two variables including drought duration, severity and inter-arrival time, employing a trivariate Placket copula. In the other their study, they applied 
various metaelliptical copulas (Gumbel-Hougaard, Clayton, Frank and Ali Mikhail-Haq) to obtain trivariate joint distributions of drought variables (Song and Singh 2010b).

A few studies have been performed for bivariate frequency analysis of any specific region in Turkey using copula functions. For this reason, this paper's goal is to investigate the univariate and bivariate distribution and derive the joint probability distribution of meteorological drought in Ceyhan Basin, Turkey. To achieving this purpose, (1) monthly precipitation data from 24 meteorological stations located in the Ceyhan basin are gathered and the Mann-Kendall trend test is employed to determine the homogeneous precipitation basin, (2) the Standard Precipitation Index (SPI) method is used to identify drought variable (severity and duration) and to test their stationary and randomness, Mann-Kendall and Spearman Rho Tests are performed, (3) the best-fit marginal distributions of drought severity and duration are determined respectively, (4) ten types of copulas (i.e., Gaussian copula, Student t copula (tcopula), Clayton copula, Gumbel copula, Frank copula, Joe copula, BB1 copula, BB6 copula, BB7 copula and BB8 copula) are applied to generate two-dimensional joint distributions and (5) consideration with upper and lower tail dependence, the best fit copula for each stationary station, significant probabilistic specifications of droughts are derived. After all, results are presented and discussed.

\section{Methods}

\subsection{Definition of Drought Events}

In this study, the standard precipitation index (SPI) developed by Mckee et al. (1993) was carried out for identifying drought events (Fig. 1). The main advantage of using SPI is statistical consistency. It also enables us to define both short-term and long-term drought effects at different time scales of precipitation anomalies. In statistics, the SPI value is equivalent to the Z-score. However, due to precipitation observations with a time scale of 12 month or less, the distribution of observation is generally considered skewed. The more appropriate distribution for precipitation data is found as gamma distribution by (Thom 1958). The probability density function can be calculated for gamma distribution $\mathrm{g}$ $(\mathrm{x})$;

$$
g(x)=\frac{1}{\beta \Gamma(\alpha)} x^{\alpha-1} e^{-\frac{x}{\beta}}
$$

1

where $\mathrm{x}$ is precipitation observation, $\alpha>0$ and $\beta>0$ are shape and scale parameter. The gamma function $\Gamma(\alpha)$ is defined as;

$$
\Gamma(\alpha)=\int_{0}^{\infty} \mathrm{y}^{\alpha-1} \mathrm{e}^{-\mathrm{y}} \mathrm{dy}
$$

2

Edwards and McKee (1997) applied the maximum likelihood method for predicting $\alpha, \beta$ parameters; 


$$
\hat{\alpha}=\frac{1}{4}\left(1+\sqrt{1+\frac{4 \mathrm{~A}}{3}}\right)
$$

3

$$
\hat{\beta}=\frac{x}{\hat{\alpha}}
$$

4

where

$$
\mathrm{A}=\ln \left(\begin{array}{l}
- \\
\mathrm{x}
\end{array}\right)-\frac{\sum \ln (\mathrm{x})}{\mathrm{n}}
$$

5

$\mathrm{n}$ is the number of precipitation observations, and $\mathrm{x}$ is the mean of $\mathrm{x}$. The cumulative distribution may be defined as

$$
H(x)=q+(1-q) G(x)
$$

6

where $\mathrm{q}$ is the probability of zero and $\mathrm{G}(\mathrm{x})$ is the cumulative distribution for a desired month and time scale. Finally, the cumulative distribution $\mathrm{H}(\mathrm{x})$ is then converted to the standard normal random variable $\mathrm{Z}$ (mean zero and variance one), which represents the value of SPI (Tsakiris and Pangalou 2009). Fig. 1 explains the time series of SPI and the drought process. Mckee et al. (1993) categorized droughts as a period length in which the SPI is below - 1 and SPI classifications for wet and dry events are listed in Table 1. Drought duration (D) is expressed as the number of consecutive interval (months) where SPI value fell below zero and drought severity (S) is defined as cumulative SPI value during drought duration, stated using the following equation as (Mckee et al. 1993);

$$
\mathrm{S}=-\sum_{\mathrm{i}=1}^{\mathrm{D}} \mathrm{SPI}_{\mathrm{i}}
$$

7

where $S$ is drought severity, and $D$ is drought duration. Interval time $E(L)$ is the time between the initiation of drought to the beginning of the next drought (Mishra and Singh 2010).

\subsubsection{Measure of Dependence Drought Characteristics}


In order to employ copula function, stationarity, or independence of drought variables should be defined (Daneshkhah et al. 2016). In this study, Mann-Kendall and Spearman Rho, which are non-parametric trend tests mostly used measure of dependence, were applied to calculate serial stationarity structure of drought duration and severity. According to two test results, computed $Z$ values were lower than the critical of \pm 1.96 at 0.05 significance level (Table 2 ). That is, for fitting copula function, drought variables were displayed to be appropriate. Consequently, after proving that stationarity of random variables, bivariate copula function can be applied. However, nonstationary distribution models would be assessed, if the data were not stationary. The Mann-Kendall's non-parametric rank correlation coefficient was also employed to drought variables. Highly correlated between variables are reasonable for applying joint distribution.

\subsection{Distributions of Univariate Drought Variables}

Before constructing bivariate distribution of drought variables (duration and severity), a univariate distribution of drought characteristics must be firstly described. Some previous studies showed exponential for drought duration and gamma distribution for drought severity commonly used in drought analysis (Shiau 2006; Shiau and Modarres 2009; Lee et al. 2013). However, Yusof et al. (2013) has suggested two mostly used probability distributions are not appropriate in every case well. Therefore, several distributions are used to fit the drought severity and drought duration in this study. The distributions are Lognormal, Logistic, Gamma, Exponential, Weibull and Normal distributions. The performance of used distributions for each drought characteristic are tested by the Anderson-Darling (AD) (Stephens 1974), Kolmogorov-Smirnov (K-S) (Smirnov 1948), Cramers-von Mises (CvM), Akaike's Information Criterion (AIC) (AKAIKE 1976), Bayesian Information Criterion (BIC) (Stone 1979) and Maximum likelihood methods.

\subsection{Copula Functions}

The copula is a powerful function that enables us to model a joint distribution function of different univariate random variables (Nelsen 2007), and it is based on the correlation between variables to link different marginal distribution. When compared to traditional multivariate distributions, copula provides great flexibility to select the univariate marginal distributions. The theoretical definition of a copula was first expressed by SKLAR (1959). According to Sklar's theorem, if two random variables $x$ and $y$ are considered with their following the marginal distribution function $F_{X}(x)$ and $F_{Y}(y)$ respectively, then there exists a unique copula $C$, where links these two different marginal to model the joint distribution function, $F_{X, Y}(x, y)$. C is defined using the following equation as (Nelsen 2007);

$$
\mathrm{F}_{\mathrm{X}, \mathrm{Y}}(\mathrm{x}, \mathrm{y})=\mathrm{C}\left(\mathrm{F}_{\mathrm{X}}(\mathrm{x}), \mathrm{F}_{\mathrm{Y}}(\mathrm{y})\right)
$$

8

Equation 8 shows that a copula can define a multivariate distribution concerning a univariate distribution. Conversely, for any univariate distributions $F_{X}(x)$ and $F_{Y}(y)$ and any copula $\mathrm{C}$, the function $F_{X, Y}(x, y)$ stated above is a two-dimensional distribution function with marginal distributions $F_{X}(x)$ and $F_{Y}(y)$. 
Additionally, if $F_{X}(x)$ and $F_{Y}(y)$ are continuous, then $C$ is completely unique (Shiau 2006). Then the joint probability density function defines the following;

$$
f_{X, Y}(x, y)=c\left(F_{X}(x), F_{Y}(y)\right) f_{X}(x) f_{Y}(y)
$$

9

where $f_{X}(x)$ and $f_{Y}(y)$ are the density functions related to $F_{X}(x)$ and $F_{Y}(y)$, respectively, and $\mathrm{c}$ is the density function of $\mathrm{C}$, defined as

$$
c(u, v)=\frac{\partial^{2} C(u, v)}{\partial u \partial v}
$$

10

where $\mathrm{u}=F_{X}(x)$ and $\mathrm{v}=F_{Y}(y)$.

while many copula families exist including (1) Archimedean (Gumbel, Frank, Clayton and Ali-MikhailHaq); (2) Elliptical (normal and t); Extreme Value (Galambos, Gumbel, Husler-Reiss etc.) and other families (Farlie-Gumbel-Morgenstern, Plackett, BB1, BB6, BB7 and BB8), just Archimedean is convenient for hydrologic applications (Joe 1997; Abdous et al. 2005; Nelsen 2007). One parameter Archimedean copula can be defined as (Nelsen 2007)

$\operatorname{co}(\mathrm{u}, \mathrm{v})=\phi^{-1}\{\varnothing(\mathrm{u})+\{\varnothing(\mathrm{v})\} \quad 0<\mathrm{u}<1,<\mathrm{v}<1$

where $\varnothing[0,1]$ is copula generating function and $\emptyset(1)=0$. The summary description of copula families used in the study is shown in Table 3.

\subsection{Tail Dependence Assessments}

The terms of upper and lower tail dependence were introduced by Sibuya (1960), which are related to dependence between extreme values in the upper and lower tails of the bivariate distribution. The lower positive values of the upper tail show that they are of poor relation or not strongly dependent (Reddy and Ganguli 2012). In hydrology, disregarding tail dependencies can cause high uncertainty in extreme quantile predictions, resulting in incorrect findings for hydrological design (Xu et al. 2010). On the other hand, frequency analysis of extreme hydrological events (such as droughts and floods) should be considered in terms of tail dependencies (Poulin et al. 2007). The coefficient of upper (lower) tail dependence $\lambda_{u}\left(\lambda_{L}\right)$ is defined as

\section{$\lambda_{\mathrm{u}}=\lim _{\mathrm{t} \rightarrow 1^{-}} \mathrm{P}\left\{\mathrm{F}_{\mathrm{X}}(\mathrm{x})>\mathrm{t} \mid \mathrm{F}_{\mathrm{Y}}(\mathrm{y})>\mathrm{t}\right\}$}




\section{$\lambda_{\mathrm{L}}=\lim _{\mathrm{t} \rightarrow 0^{+}} \mathrm{P}\left\{\mathrm{F}_{\mathrm{X}}(\mathrm{x})<\mathrm{t} \mid \mathrm{F}_{\mathrm{Y}}(\mathrm{y})<\mathrm{t}\right\}$}

Where $F_{X}(x), F_{Y}(y)$ are CDFs of random variables of drought duration and severity, respectively, and $t$ is the constant value standard uniform variable. If $\lambda_{u}\left(\lambda_{L}\right) \in(0,1]$ bivariate distribution function can be said to show upper (lower) tail dependence and if $\lambda_{u}\left(\lambda_{L}\right)=0$, variables are independent. The upper (lower) tail dependence can be expressed in term of copula function as

$$
\lambda_{\mathrm{u}}=\lim _{\mathrm{t} \rightarrow 1^{-}} \frac{1-2 \mathrm{t}+\mathrm{C}(\mathrm{t}, \mathrm{t})}{1-\mathrm{t}}
$$

14

$\lambda_{\mathrm{L}}=\lim _{\mathrm{t} \rightarrow 1^{-}} \frac{\mathrm{C}(\mathrm{t}, \mathrm{t})}{\mathrm{t}}$

Tail dependence just applies to choose an appropriate copula family (not on the selection of marginal distribution). Previous studies showed that the best fit copula is Clayton without using tail dependence. However, with using tail dependence, while non-Gaussian copulas have a quite lower upper (lower) tail dependency, Gaussian copula doesn't have tail dependence (AghaKouchak et al. 2010). This paper is focused on upper tail dependence due to analyzing the occurrence of extreme events. That is, according to test results and literature, Ali-Mikhail -Haq $\left(\lambda_{u}=0, \lambda_{L}=0\right)$,Frank $\left(\lambda_{u}=0, \lambda_{L}=0\right)$, Galambos $\left(\lambda_{u} \neq 0, \lambda_{L}=0\right)$ and Plackett $\left(\lambda_{u}=0, \lambda_{L}=0\right)$ copulas didn't take consideration (Nelsen 2007).

The non-parametric upper tail dependence $\left(\lambda_{u}^{C F G}\right)$ is given by the following

$$
\lambda_{\mathrm{u}}^{\mathrm{CFG}}=2-2 \operatorname{ex}\left\{\frac{1}{\mathrm{n}} \sum_{\mathrm{i}=1}^{\mathrm{n}} \log \left\{\frac{\sqrt{\log \left(\frac{1}{\mathrm{u}_{1}}\right) \log \left(\frac{1}{\mathrm{v}_{1}}\right)}}{\log \left(\frac{1}{\max \left(\mathrm{u}_{1}, \mathrm{v}_{1}\right)^{2}}\right)}\right\}\right.
$$

16

\subsection{Return Period}

A general approach to the management of the water resources system, hydrologic and hydraulic facilities, is to estimate return periods of drought characteristics (Shiau and Shen 2001). Mainly, drought return periods give crucial information under drought conditions. Univariate return of drought duration greater than or equal to a certain value can be calculated as 


$$
\mathrm{T}_{\mathrm{D}}=\frac{\mathrm{E}(\mathrm{L})}{1-\mathrm{F}_{\mathrm{D}}(\mathrm{d})}
$$

\section{7}

where $L$ is expected drought interval time, which mentioned in 2.1, $T_{D}$ is the return period defined solely by drought duration. The return period of drought severity, greater than or equal to a certain value, can be obtained using the same formula defined as

$\mathrm{T}_{\mathrm{S}}=\frac{\mathrm{E}(\mathrm{L})}{1-\mathrm{F}_{\mathrm{S}}(s)}$

Joint drought duration and severity can be estimated in two cases: return period for $D \geq d$ and $S \geq s$ and joint return period for $\mathrm{D} \geq \mathrm{d}$ and $\mathrm{S} \geq \mathrm{s}$ which is stated by $T_{D S}$ and $T_{D S}^{\prime}$, respectively, as follows:

$$
\begin{gathered}
\mathrm{T}_{\mathrm{DS}}=\frac{\mathrm{E}(\mathrm{L})}{\mathrm{P}(\mathrm{D} \geq \mathrm{d}, \mathrm{S} \geq \mathrm{s})}=\frac{\mathrm{E}(\mathrm{L})}{1-\mathrm{F}_{\mathrm{D}}(\mathrm{d})-\mathrm{F}_{\mathrm{S}}(\mathrm{s})+\mathrm{F}_{\mathrm{DS}}(\mathrm{d}, \mathrm{s})} \\
=\frac{\mathrm{E}(\mathrm{L})}{1-\mathrm{F}_{\mathrm{D}}(\mathrm{d})-\mathrm{F}_{\mathrm{S}}(\mathrm{s})+\mathrm{C}\left(\mathrm{F}_{\mathrm{D}}(\mathrm{d}), \mathrm{F}_{\mathrm{S}}(\mathrm{s})\right)}
\end{gathered}
$$

19

$$
\begin{gathered}
\mathrm{T}^{\prime}{ }_{\mathrm{DS}}=\frac{\mathrm{E}(\mathrm{L})}{\mathrm{P}(\mathrm{D} \geq \mathrm{d} \text { or } \mathrm{S} \geq \mathrm{s})}=\frac{\mathrm{E}(\mathrm{L})}{1-\mathrm{F}_{\mathrm{DS}}(\mathrm{d}, \mathrm{s})} \\
=\frac{\mathrm{E}(\mathrm{L})}{1-\mathrm{C}\left(\mathrm{F}_{\mathrm{D}}(\mathrm{d}), \mathrm{F}_{\mathrm{S}}(\mathrm{s})\right)}
\end{gathered}
$$

20

where $F_{S}(s)$ and $F_{D}(d)$ are CDFs of univariate of drought severity, duration and $C$ is any type of copula, respectively.

\section{Study Area And Data}

The Ceyhan basin is located between latitudes of 36ख30' and longitudes of $35 \varangle 20$ ' in the eastern Mediterranean region of Turkey. It is bordered by the Asi in the south, the Seyhan Basin in the west and northwest, and the Euphrates in the east and northeast (Fig. 2) (Tanrıverdi et al. 2010). Ceyhan basin, covering an area of about $20.670 \mathrm{~km}^{2}$, includes three central provinces, namely Adana, Kahramanmaras and Osmaniye. According to the rainfall regime of the Mediterranean climate type in Ceyhan Basin, while the rainiest season is winter (December, January, February), the least rainfall in summer (June, July, August). The characteristics of the Mediterranean climate are generally seen in the basin. Ceyhan Basin is under the influence of different pressure centers. However, the influence of these pressure centers varies during the year. The climate of the Ceyhan basin is of arid environment, where rainfalls are 
infrequent with short duration in summer. The annual depth of evaporation is low, varying from $0 \mathrm{~mm}$ to $325 \mathrm{~mm}$. evaporation increases significantly in summer, where significant evaporation occurred in June, July and August. In contrast, it decreases in winter, especially in December, January and February. The Ceyhan River's total length is $425 \mathrm{~km}$, its annual discharge is $82.9 \mathrm{~m}^{3} / \mathrm{sec}$ and the basin yield is $10.7 \mathrm{~L}$ / $\mathrm{h} / \mathrm{km}^{3}$. The total annual rainfall is seen in Kozan at least $842 \mathrm{~mm}$, and the lowest rainfall area of the basin is in Elbistan, with $395.7 \mathrm{~mm}$. The average annual temperature is at most in Kozan $\left(19.3^{\circ} \mathrm{C}\right)$ and at least in Göksun (8.9 $\left.{ }^{\circ} \mathrm{C}\right)$ (Eris et al. 2019; Yuce et al. 2019; Yuce and Esit 2021).

A total of 24 gauging stations which distributed evenly were selected in the Ceyhan basin and its surrounding areas (Fig. 2). The monthly precipitation data were obtained from the National General Directorate of Meteorology. The distribution of annual depth of precipitation data is shown in Fig. 3. According to Figure, while the highest distribution annual depth of precipitation is seen lower basin as $381 \mathrm{~mm}$, the lowest distribution depth of precipitation occurs upper basin as $894 \mathrm{~mm}$.

\section{Results}

\subsection{Marginal Distribution of Drought Variables}

Firstly, Drought characteristics are calculated from monthly precipitation data for each station using SPI (1, 3-and 6-time scales) demonstrated in Fig. 4. Before determining the best fit copula, the univariate marginal distributions should be determined for each drought variable. As stated above, section 2.2, some researchers found that the other distributions families such as Weibull, Lognormal, etc. can be more appropriate than the most used distribution functions. According to the test results' performance, Weibull and Lognormal distribution for drought duration, Weibull and Gamma distribution for drought severity are more convenient, respectively (Table 4). The parameters for each distribution are estimated using the performance of the test mentioned in section 2.2. An example frequency analysis of selected appropriate marginal distributions, Weibull for duration and gamma for severity, are shown in Fig. 5. The probability density function (Pdf) of Weibull is defined as:

$f_{S \mid D}(s \mid d)=\frac{\beta(s \mid d)^{\beta-1}}{\eta^{\beta}} e^{-\left(\frac{(s \mid d)}{\eta}\right)^{\beta}, \mathrm{s} \mid \mathrm{d}>0(21)}$

where $\mathrm{s} \mid \mathrm{d}$ is drought severity| duration; $\eta$ and $\beta$ are scale and shape parameter, respectively. The probability density function of the gamma distribution is as follows:

$f_{S \mid D}(s \mid d)=\frac{(s \mid d)^{a-1}}{\beta^{a} \Gamma(a)} e^{-\frac{(s \mid d)}{\beta}}, \mathrm{s} \mid \mathrm{d}>0$ (22)

where $\Gamma$ is gamma function, $\alpha, \beta$ are shape and scale parameter. The probability density function of Lognormal is expressed as: 
$f_{S \mid D}(s \mid d)=\frac{1}{\beta_{N}(s \mid d) \sqrt{2 \pi}} \exp \left[-\frac{1}{2}\left(\frac{\ln (s \mid d)-a_{N}}{\beta_{N}}\right)^{2}\right], s \mid d>0$ (23)

\subsection{Estimation of Joint Distributions}

After getting drought characteristics with fitted marginal distributions, ten copula functions, including Gaussian, Student t, Clayton, Gumbel, Frank, Joe, BB1, BB6, BB7 and BB8 copula, were tested to determine the best fit copula for modeling the dependence between drought duration and severity. Their performance for each SPI time scale (1,3 and 6 month) was tested by Akaike's Information Criterion (AIC), Bayesian Information Criterion (BIC) and Maximum likelihood methods. Also, visual tests were generated and simulated 10,000 random pairs $\left(u_{1}, v_{1}\right)$ for the selected best copula (Fig. 6 ).

The other main focus for selecting the best fit copula is to evaluate tail dependence. Descriptive information is stated in section 2.5. The comparison of simulated copula functions (Figure 6) versus observed drought duration and severity shows that higher dependence is not the lower tail between $u_{1}$ and $v_{1}$. That is, higher dependencies indicate the upper tail. While test performances results demonstrate

Ali-Mikhail -Haq $\left(\lambda_{u}=0, \lambda_{L}=0\right)$, Frank $\left(\lambda_{u}=0, \lambda_{L}=0\right)$, Galambos $\left(\lambda_{u} \neq 0, \lambda_{L}=0\right)$ and Plackett $\left(\lambda_{u}=0, \lambda_{L}=0\right)$ functions are not convenient for the bivariate distribution function according to tail dependence and Kendall tau results. Table 5 illustrates that the Gaussian copula seems appropriate for selected stations due to the lowest AIC, BIC, and highest Log-likelihood value without considering tail dependence and Kendall coefficient. BB1 and Gumbel copula is performing better than Gaussian and Clayton copula due to the absence of tail dependence. BB1 and Gumbel copulas show a small differential in terms of tail dependence, and the CFG estimator computed 0.728 for the selected station. Since Log-likelihood and AIC values are slightly higher than Gumbel copula, the BB1 copula is suitable for bivariate drought analysis.

Univariate and bivariate return periods for the selected station are shown in Table 5. Drought duration and severity are found well fitted as Weibull distribution (parameters; $\eta=1.47$ and $\beta=3.95$ ) and gamma distribution (parameters; $\alpha=0.82$ and $\beta=0.27$ ), respectively. Univariate for each drought events are obtained using eq. 17 and 18. Interarrival time $\mathrm{E}(\mathrm{L})$ is estimated as 0.618 month considering drought time between the initiation of drought to the beginning of the next drought. After this process, return periods of $10,20,50,100,200$ and 500 years evaluated by drought duration and severity are summarized separately as shown in Table 6. The joint return period for drought events can be estimated in two cases: return period for $\mathrm{D} \geq \mathrm{d}$ and $\mathrm{S} \geq \mathrm{s}$ and joint return period for $\mathrm{D} \geq \mathrm{d}$ and $\mathrm{S} \geq \mathrm{s}$, which is stated by $T_{D S}$ and $T_{D S}^{\prime}$ respectively, using eq. 19 and 20. BB1 copula parameters are found as 0.12 and 2.84 that is evaluated using the maximum likelihood method considering best-fitted drought events marginal distributions parameters. The joint return period of drought events for the two cases, $\mathrm{T}_{\mathrm{DS}}$ and $\mathrm{T}^{\prime}{ }_{\mathrm{DS}}$, are presented in Figure 7 (17255, SPI3). 
In this paper, the joint return period of drought duration and severity for different return periods $(10,20,50$, 100, 200 and 500 years) is estimated employing the best fit copula for all stations. Here, station 17255 is shown as an example to clarify the copula process. For instance, the joint return period $\mathrm{T}_{\mathrm{DS}}$ for drought duration and severity exceeding 11.90 month and 16.63 is approximately 137.9 years, whereas it is 100 years for the univariate return period and 78.4 years for the joint return period of $T_{D S}^{\prime}$. Hence, drought events should be evaluated based on derived copula. Hydrologic facilities in terms of water resources system and the significant drought characteristics can be considered the possible maximum duration likely to happen over social and economic life (Mishra and Singh, 2010).

After evaluating the joint return period of drought duration and severity for each station, the spatial distributions of $T_{D S}$ and $T_{D S}^{\prime}$ for return periods under case 1 and case 2 (SPI1, SPI3 and SPI6 years) are presented in Figure 8-10. Drought risk categories are described as light, moderate, severe and extreme droughts considering a specific threshold for drought duration and severity, respectively. (Chang et al. 2016). The percentile method (\%25, \%50, \%75 and \%95), which is mentioned in (Chang et al. 2016) in detail, was employed to the marginal distribution of drought duration and severity series considered to four drought risk categories.

The first scenario for the SPI1 time scale, indicates that the eastern part is mostly dominated by relatively lower drought risk (maximum $T_{D S}$ (left) and $T_{D S}^{\prime}$ (right)) at all categories. In contrast, southwestern region shows a relatively higher drought risk, indicating lower $T_{D S}$ and $T_{D S}^{\prime}$. For all drought risk categories, the return periods of $T_{D S}$ are generally longer than $T_{D S}^{\prime}$ and they show a good consistency except the northern part. While the northern regions largely experience higher $T_{D S}$ under all stated drought conditions, shorter return periods $T_{D S}^{\prime}$ (high-risk) are exhibited in northern regions (Figure 8).

Second scenarios for SPI 3-time scale, compared to the southern regions, the northern regions, under all drought categories, especially D20M001 and D20M011, higher return period $T_{D S}$ and $T_{D S}^{\prime}$ (lower risk) are observed. But the western part shows a tendency to decrease the risk from light to extreme category for $T_{D S} . T_{D S}^{\prime}$ exhibits higher risk in this region. When examined the middle part of the basin, high risks are observed for all $T_{D S}$ and $T_{D S}^{\prime}$ under light drought categories.

The last scenario for SPI 6-time scale, under all drought risk conditions, the northeastern and slightly western regions generally indicate the same conditions with a higher return period of $T_{D S}$ and $T_{D S}^{\prime}$. In comparison, the northwestern regions exhibit a lower return period of $T_{D S}$ and $T_{D S}^{\prime}$ (high risk), except higher both return periods under all drought categories. Focusing on the outcomes of $T_{D S}^{\prime}$ on the light drought categories, stations of D20M006 and 17868 show high risk due to lower return period.

\section{Summary And Conclusions}

Since drought is a complex phenomenon, understanding drought variable is great of importance for water resource management. In this study, bivariate drought analysis was applied based on copula functions. The previous studies mainly focused on that drought risk assessments are evaluated by using a single 
variable. However, drought should be assessed employing multiple variables together due to affecting various parameters. Hence, bivariate copula functions are essential to construct a link between drought variables.

In this study, drought events were defined by standard precipitation index (SPI) series when the index below zero. After acquiring drought duration and severity, they are fitted separately by the different probabilistic distribution functions. Ten copula functions, including Gaussian, Student t, Clayton, Gumbel, Frank, Joe, BB1, BB6, BB7 and BB8 copula, are considered to determine the best fit copula for modeling the dependence between correlated drought duration and severity. Apart from employing several statistical tests (Akaike's Information Criterion (AIC), Bayesian Information Criterion (BIC) and Maximum likelihood methods), the performance of different copula classes are evaluated in terms of upper tail dependence. After performing statistical and tail dependence tests for modeling the best copula function for each station, based on the joint distribution function, the drought severity - duration - frequency (SDF) of various recurrence intervals for all stations are derived.

Spatial distribution joint return period of $T_{D S}$ and $T_{D S}^{\prime}$ considering drought risk assessment based on percentile method (\%25, \%50, \%75 and \%95) are displayed at four different categories (light, moderate, severe, and extreme drought). Based on categorizing drought return periods, their interpreting provides clear information about drought analysis. According to the results, lower return periods should be considered high risk for drought occurrence that could negatively affect water quality, water suppliers and soil moistures. Hence, the southwestern region exhibits more drought risk than the other region under all categories at the SPI 1-time scale. When considered SPI 3 and SPI 6-time scales, the high drought risk generally is expected to experience in the middle part of the basin except for the light drought category of

SPI6 $T_{D S}^{\prime}$ return period. The higher drought risk is shown in the northwestern region for $T_{D S}$ while a higher return period was detected under the light category for the $T_{D S}^{\prime}$ return period. However, the outcomes of $T_{D S}^{\prime}$ on the light drought categories, stations of D20M018 and 17868, show high risk due to the lower return period. The finding of this paper may help the planning of future water resource management and mitigation of drought impact in the Ceyhan Basin.

\section{Declarations}

\section{Data availability and materials}

The data that support the findings of this study are available from the corresponding author upon request.

Confict of interest The authors declare no confict of interest

\section{References}


1. Abdous B, Genest C, Rémillard B (2005) Dependence Properties of Meta-Elliptical Distributions.. In: In: Duchesne P, RÉMillard B (eds) Statistical Modeling and Analysis for Complex Data Problems. Springer US, Boston, MA, pp 1-15

2. AghaKouchak A, Bárdossy A, Habib E (2010) Conditional simulation of remotely sensed rainfall data using a non-Gaussian v-transformed copula. Adv Water Resour 33:624-634. https://doi.org/10.1016/j.advwatres.2010.02.010

3. Ahmadi F, Radmaneh F, Sharifi MR, Mirabbasi R (2018) Bivariate frequency analysis of low flow using copula functions (case study: Dez River Basin, Iran). Environ Earth Sci 77:643. https://doi.org/10.1007/s12665-018-7819-2

4. AKAIKE H (1976) An information criteron (AIC). Math Sci 14:5-7

5. Alamgir M, Ismail T, Noor M (2018) Bivariate Frequency Analysis of Flood Variables Using Copula in Kelantan River Basin. Malays J Civ Eng 30. https://doi.org/10.11113/mjce.v30n3.515

6. Bárdossy A (2006) Copula-based geostatistical models for groundwater quality parameters. Water Resour Res 42. https://doi.org/10.1029/2005WR004754

7. Bonaccorso B, Cancelliere A, Rossi G (2003) An analytical formulation of return period of drought severity. Stoch Environ Res Risk Assess 17:157-174. https://doi.org/10.1007/s00477-003-0127-7

8. Cancelliere A, Mauro GD, Bonaccorso B, Rossi G (2007) Drought forecasting using the Standardized Precipitation Index. Water Resour Manag 21:801-819. https://doi.org/10.1007/s11269-006-9062-y

9. Cancelliere A, Salas JD (2004) Drought length properties for periodic-stochastic hydrologic data. Water Resour Res 40. https://doi.org/10.1029/2002WR001750

10. Chacon-Hurtado JC, Alfonso L, Solomatine DP (2017) Rainfall and streamflow sensor network design: a review of applications, classification, and a proposed framework. Hydrol Earth Syst Sci 21:3071-3091. https://doi.org/10.5194/hess-21-3071-2017

11. Chang J, Li Y, Wang Y, Yuan M (2016) Copula-based drought risk assessment combined with an integrated index in the Wei River Basin, China. J Hydrol 540:824-834.

https://doi.org/10.1016/j.jhydrol.2016.06.064

12. Chen H, Sun J (2015) Changes in Drought Characteristics over China Using the Standardized Precipitation Evapotranspiration Index. J Clim 28:5430-5447. https://doi.org/10.1175/JCLI-D-1400707.1

13. Chen L, Singh VP, Guo S et al (2013) Drought Analysis Using Copulas. J Hydrol Eng 18:797-808. https://doi.org/10.1061/(ASCE)HE.1943-5584.0000697

14. Daneshkhah A, Remesan R, Chatrabgoun O, Holman IP (2016) Probabilistic modeling of flood characterizations with parametric and minimum information pair-copula model. J Hydrol 540:469487. https://doi.org/10.1016/j.jhydrol.2016.06.044

15. Dong Q, Zhang X, Lall U et al (2019) An improved nonstationary model for flood frequency analysis and its implication for the Three Gorges Dam, China. Hydrol Sci J 64:845-855.

https://doi.org/10.1080/02626667.2019.1596274 
16. Durocher M, Burn DH, Mostofi Zadeh S (2018) A nationwide regional flood frequency analysis at ungauged sites using ROI/GLS with copulas and super regions. J Hydrol 567:191-202. https://doi.org/10.1016/j.jhydrol.2018.10.011

17. Eris E, Aksoy H, Onoz B et al (2019) Frequency analysis of low flows in intermittent and nonintermittent rivers from hydrological basins in Turkey. Water Supply 19:30-39. https://doi.org/10.2166/ws.2018.051

18. Esit M, Kumar S, Pandey A et al (2021) Seasonal to multi-year soil moisture drought forecasting. Npj Clim Atmospheric Sci 4:1-8. https://doi.org/10.1038/s41612-021-00172-z

19. GUMBEL EJ (1963) Statistical Forecast of Droughts. Int Assoc Sci Hydrol Bull 8:5-23. https://doi.org/10.1080/02626666309493293

20. Guttman NB (1998) Comparing the Palmer Drought Index and the Standardized Precipitation Index1. JAWRA J Am Water Resour Assoc 34:113-121. https://doi.org/10.1111/j.1752-1688.1998.tb05964.x

21. Hui-Mean F, Yusof F, Yusop Z, Suhaila J (2019) Trivariate copula in drought analysis: a case study in peninsular Malaysia. Theor Appl Climatol 138:657-671. https://doi.org/10.1007/s00704-019-028473

22. Joe H (1997) Multivariate Models and Multivariate Dependence Concepts. CRC Press

23. Kao S-C, Govindaraju RS (2010) A copula-based joint deficit index for droughts. J Hydrol 380:121134. https://doi.org/10.1016/j.jhydrol.2009.10.029

24. Kim T-W, Valdés JB, Yoo C (2003) Nonparametric Approach for Estimating Return Periods of Droughts in Arid Regions. J Hydrol Eng 8:237-246. https://doi.org/10.1061/(ASCE)10840699(2003)8:5(237)

25. Kuhn G, Khan S, Ganguly AR, Branstetter ML (2007) Geospatial-temporal dependence among weekly precipitation extremes with applications to observations and climate model simulations in South America. Adv Water Resour 30:2401-2423. https://doi.org/10.1016/j.advwatres.2007.05.006

26. Kwon H-H, Lall U (2016) A copula-based nonstationary frequency analysis for the 2012-2015 drought in California. Water Resour Res 52:5662-5675. https://doi.org/10.1002/2016WR018959

27. Lee T, Modarres R, Ouarda TBMJ (2013) Data-based analysis of bivariate copula tail dependence for drought duration and severity. Hydrol Process 27:1454-1463. https://doi.org/10.1002/hyp.9233

28. Linsley RK, Kohler MA, Paulhus JLP (1949) Applied hydrology. Civ Eng Ser USA Eng

29. Masud MB, Khaliq MN, Wheater HS (2015) Analysis of meteorological droughts for the Saskatchewan River Basin using univariate and bivariate approaches. J Hydrol 522:452-466. https://doi.org/10.1016/j.jhydrol.2014.12.058

30. Mckee T, Doesken N, Kleist J (1993) The Relationship of Drought Frequency and Duration To Time Scales. In Proceedings of the 8th Conference on Applied Climatology (Vol. 17, No. 22, pp. 179-183)

31. Mirabbasi R, Fakheri-Fard A, Dinpashoh Y (2012) Bivariate drought frequency analysis using the copula method. Theor Appl Climatol 108:191-206. https://doi.org/10.1007/s00704-011-0524-7 
32. Mishra AK, Singh VP (2009) Analysis of drought severity-area-frequency curves using a general circulation model and scenario uncertainty. J Geophys Res Atmospheres 114. https://doi.org/10.1029/2008JD010986

33. Mishra AK, Singh VP (2010) A review of drought concepts. J Hydrol 391:202-216. https://doi.org/10.1016/j.jhydrol.2010.07.012

34. Nelsen RB (2007) An Introduction to Copulas. Springer Science \& Business Media

35. Organization (WMO) WM, World Meteorological Organization (WMO) (1986) WCP, 118. Report on drought and countries affected by drought during 1974-1985. WMO, Geneva

36. Palmer WC (1965) Meteorological Drought. U.S. Department of Commerce, Weather Bureau

37. Poulin A, Huard D, Favre A-C, Pugin S (2007) Importance of Tail Dependence in Bivariate Frequency Analysis. J Hydrol Eng 12:394-403. https://doi.org/10.1061/(ASCE)1084-0699(2007)12:4(394)

38. Reddy MJ, Ganguli P (2012) Application of copulas for derivation of drought severity-durationfrequency curves. Hydrol Process 26:1672-1685. https://doi.org/10.1002/hyp.8287

39. Salas JD, Fu C, Cancelliere A et al (2005) Characterizing the Severity and Risk of Drought in the Poudre River, Colorado. J Water Resour Plan Manag 131:383-393. https://doi.org/10.1061/(ASCE)0733-9496(2005)131:5(383)

40. Salvadori G, Michele CD, Kottegoda NT, Rosso R (2007) Extremes in Nature: An Approach Using Copulas. Springer Science \& Business Media

41. Schneider DSH (2011) Encyclopedia of Climate and Weather. OUP USA

42. Serinaldi F, Bonaccorso B, Cancelliere A, Grimaldi S (2009) Probabilistic characterization of drought properties through copulas. Phys Chem Earth Parts ABC 34:596-605. https://doi.org/10.1016/j.pce.2008.09.004

43. She D, Xia J (2018) Copulas-Based Drought Characteristics Analysis and Risk Assessment across the Loess Plateau of China. Water Resour Manag 32:547-564. https://doi.org/10.1007/s11269-017$1826-z$

44. Sheffield J, Wood EF, Roderick ML (2012) Little change in global drought over the past 60 years. Nature 491:435-438. https://doi.org/10.1038/nature11575

45. Shiau JT (2006) Fitting Drought Duration and Severity with Two-Dimensional Copulas. Water Resour Manag 20:795-815. https://doi.org/10.1007/s11269-005-9008-9

46. Shiau J-T, Feng S, Nadarajah S (2007) Assessment of hydrological droughts for the Yellow River, China, using copulas. Hydrol Process 21:2157-2163. https://doi.org/10.1002/hyp.6400

47. Shiau JT, Modarres R (2009) Copula-based drought severity-duration-frequency analysis in Iran. Meteorol Appl 16:481-489. https://doi.org/10.1002/met.145

48. Shiau J-T, Modarres R, Nadarajah S (2012) Assessing Multi-site Drought Connections in Iran Using Empirical Copula. Environ Model Assess 17:469-482. https://doi.org/10.1007/s10666-012-9318-2

49. Shiau J-T, Shen HW (2001) Recurrence Analysis of Hydrologic Droughts of Differing Severity. J Water Resour Plan Manag 127:30-40. https://doi.org/10.1061/(ASCE)0733-9496(2001)127:1(30) 
50. Sibuya M (1960) Bivariate extreme statistics, I. Ann Inst Stat Math 11:195-210. https://doi.org/10.1007/BF01682329

51. SKLAR M (1959) Fonctions de repartition a n dimensions et leurs marges. Publ Inst Stat Univ Paris 8:229-231

52. Smirnov N (1948) Table for Estimating the Goodness of Fit of Empirical Distributions. Ann Math Stat 19:279-281

53. Song S, Singh VP (2010a) Meta-elliptical copulas for drought frequency analysis of periodic hydrologic data. Stoch Environ Res Risk Assess 24:425-444. https://doi.org/10.1007/s00477-0090331-1

54. Song S, Singh VP (2010b) Frequency analysis of droughts using the Plackett copula and parameter estimation by genetic algorithm. Stoch Environ Res Risk Assess 24:783-805. https://doi.org/10.1007/s00477-010-0364-5

55. Stephens MA (1974) EDF Statistics for Goodness of Fit and Some Comparisons. J Am Stat Assoc 69:730-737. https://doi.org/10.1080/01621459.1974.10480196

56. Stone M (1979) Comments on Model Selection Criteria of Akaike and Schwarz. J R Stat Soc Ser B Methodol 41:276-278

57. Tanrıverdi Ç, Alp A, Demirkıran AR, Üçkardeş F (2010) Assessment of surface water quality of the Ceyhan River basin, Turkey. Environ Monit Assess 167:175-184. https://doi.org/10.1007/s10661009-1040-4

58. Thom HCS (1958) A Note on the Gamma Distribution. Mon Weather Rev 86:117-122. https://doi.org/10.1175/1520-0493

59. Tosunoglu F, Can I (2016) Application of copulas for regional bivariate frequency analysis of meteorological droughts in Turkey. Nat Hazards 82:1457-1477. https://doi.org/10.1007/s11069016-2253-9

60. Tosunoglu F, Kisi O (2016) Joint modelling of annual maximum drought severity and corresponding duration. J Hydrol 543:406-422. https://doi.org/10.1016/j.jhydrol.2016.10.018

61. Tsakiris G, Pangalou D (2009) Drought Characterisation in the Mediterranean.. In: In: Iglesias A, Cancelliere A, Wilhite DA et al (eds) Coping with Drought Risk in Agriculture and Water Supply Systems: Drought Management and Policy Development in the Mediterranean. Springer Netherlands, Dordrecht, pp 69-80

62. Vazifehkhah S, Tosunoglu F, Kahya E (2019) Bivariate Risk Analysis of Droughts Using a Nonparametric Multivariate Standardized Drought Index and Copulas. J Hydrol Eng 24:05019006. https://doi.org/10.1061/(ASCE)HE.1943-5584.0001775

63. Wang C (2016) A joint probability approach for coincidental flood frequency analysis at ungauged basin confluences. Nat Hazards 82:1727-1741. https://doi.org/10.1007/s11069-016-2265-5

64. Wang F, Wang Z, Yang H et al (2019a) Copula-Based Drought Analysis Using Standardized Precipitation Evapotranspiration Index: A Case Study in the Yellow River Basin, China. Water 11:1298. https://doi.org/10.3390/w11061298 
65. Wang F, Wang Z, Yang H et al (2019b) Copula-Based Drought Analysis Using Standardized Precipitation Evapotranspiration Index: A Case Study in the Yellow River Basin, China. Water 11:1298. https://doi.org/10.3390/w11061298

66. Wilhite D (2000) Chapter 1 Drought as a Natural Hazard: Concepts and Definitions. Drought Mitig Cent Fac Publ

67. Wilhite DA, Glantz MH (1985) Understanding: the Drought Phenomenon: The Role of Definitions. Water Int 10:111-120. https://doi.org/10.1080/02508068508686328

68. Xu Y-P, Booij MJ, Tong Y-B (2010) Uncertainty analysis in statistical modeling of extreme hydrological events. Stoch Environ Res Risk Assess 24:567-578. https://doi.org/10.1007/s00477009-0337-8

69. Yevjevich VM (1966) Objective approach to definitions and investigations of continental hydrologic droughts, An

70. Yoo J, Kim D, Kim H, Kim T-W (2016) Application of copula functions to construct confidence intervals of bivariate drought frequency curve. J Hydro-Environ Res 11:113-122. https://doi.org/10.1016/j.jher.2014.10.002

71. Yuce MI, Esit M (2021) Drought monitoring in Ceyhan Basin, Turkey. J Appl Water Eng Res 0:1-22. https://doi.org/10.1080/23249676.2021.1932616

72. Yuce MI, Esit M, Karatas MC (2019) Hydraulic geometry analysis of Ceyhan River, Turkey. SN Appl Sci 1:763. https://doi.org/10.1007/s42452-019-0800-1

73. Yusof F, Hui-Mean F, Suhaila J, Yusof Z (2013) Characterisation of Drought Properties with Bivariate Copula Analysis. Water Resour Manag 27:4183-4207. https://doi.org/10.1007/s11269-013-0402-4

74. Zhang L, Singh VP (2006) Bivariate Flood Frequency Analysis Using the Copula Method. J Hydrol Eng 11:150-164. https://doi.org/10.1061/(ASCE)1084-0699(2006)11. :2(150)

\section{Tables}

Table 1. SPI classification (Mckee et al. 1993) 


\begin{tabular}{|ll|}
\hline SPI Index & Category \\
\hline$\geq 2$ & Extremely wet \\
\hline $1.50 \sim 1.99$ & Very wet \\
\hline $1.00 \sim 1.49$ & Moderately wet \\
\hline $0.99 \sim 0$ & Normal \\
\hline $0 \sim-0.99$ & Near normal \\
\hline$-1.00 \sim-1.49$ & Moderately dry \\
\hline$-1.50 \sim-1.99$ & Severely dry \\
\hline$\leq-2$ & Extremely dry \\
\hline
\end{tabular}

Tables $2 \& 3$ are available in the Supplementary Files section.

Table 4. The numbers of marginal distribution parameters

\begin{tabular}{|c|c|c|c|c|c|c|c|}
\hline & & \multicolumn{2}{|c|}{ SPI 1} & \multicolumn{2}{|c|}{ SPI 3} & \multicolumn{2}{|c|}{ SPI 6} \\
\hline Distribution & Parameter & $\mathrm{DD}$ & DS & $\mathrm{DD}$ & DS & DD & DS \\
\hline Weibull & & 18 & 9 & 7 & 8 & 5 & 16 \\
\hline & $\eta, \beta$ & & & & & & \\
\hline Lognormal & $a, \beta$ & 6 & & 11 & 1 & 15 & \\
\hline Gamma & $a, \beta$ & & 12 & 5 & 11 & 3 & 8 \\
\hline Normal & $\mu, \sigma$ & & & 1 & 1 & & \\
\hline logistic & $\alpha, \beta$ & & & & & & \\
\hline & $\lambda^{\wedge}$ & & & & & & \\
\hline Exponential & & & 3 & & 3 & 1 & \\
\hline
\end{tabular}

Table 5. The performance of test results based on copula family for station 17255 (SPI3 timescale) 


\begin{tabular}{|c|c|c|c|c|c|c|c|c|}
\hline \multirow{2}{*}{ Number } & \multirow[b]{2}{*}{ Family } & \multirow[b]{2}{*}{$\begin{array}{l}\text { Log- } \\
\text { Lik }\end{array}$} & \multirow[b]{2}{*}{ AIC } & \multirow[b]{2}{*}{$\mathrm{BIC}$} & \multicolumn{2}{|c|}{$\begin{array}{l}\text { Tail } \\
\text { Dependence }\end{array}$} & \multirow{2}{*}{$\begin{array}{l}\text { Non- } \\
\text { parametric } \\
\text { T.D }\left({ }^{\left(\lambda_{\mathfrak{u}}^{\text {CF }}\right)}\right) \\
0.728\end{array}$} & \multirow{2}{*}{$\begin{array}{l}\begin{array}{l}\text { Kendal } \\
\text { Tau }\end{array} \\
0.749\end{array}$} \\
\hline & & & & & $\begin{array}{l}\text { Lower } \\
\text { Tail }( \\
\left.\lambda_{u}\right)\end{array}$ & $\begin{array}{l}\text { Upper } \\
\text { Tail }( \\
\left.\lambda_{\perp}\right)\end{array}$ & & \\
\hline 1 & $\begin{array}{l}\text { Gaussian } \\
\text { copula }\end{array}$ & 63.97 & -125.93 & -123.48 & & & & \\
\hline 2 & $\begin{array}{l}\text { Student t } \\
\text { copula (t- } \\
\text { copula) }\end{array}$ & 63.43 & -122.86 & -117.95 & 0.17 & 0.17 & & \\
\hline 3 & $\begin{array}{l}\text { Clayton } \\
\text { copula }\end{array}$ & 41.17 & -80.34 & -77.89 & 0.725 & & & \\
\hline 4 & $\begin{array}{l}\text { Gumbel } \\
\text { copula }\end{array}$ & 62.75 & -123.5 & -121.05 & & 0.738 & & \\
\hline 5 & Frank copula & 61.68 & -121.36 & -118.9 & & & & \\
\hline 6 & Joe copula & 56.57 & -111.14 & -108.69 & & 0.797 & & \\
\hline 7 & BB1 copula & 62.9 & -123.79 & -116.88 & 0.124 & 0.724 & & \\
\hline 8 & BB6 copula & 62.75 & -121.5 & -116.59 & & 0.738 & & \\
\hline 9 & BB7 copula & 59.71 & -115.43 & -110.52 & 0.553 & 0.768 & & \\
\hline 10 & BB8 copula & 62.33 & -120.67 & -115.76 & & & & \\
\hline
\end{tabular}

Table 6. Univariate and bivariate return periods (years) of drought events (17255, SPI3)

\begin{tabular}{lllll} 
Return periods (years) & $\mathrm{D}$ & $\mathrm{S}$ & $\mathrm{T}_{\mathrm{DS}}$ & $\mathrm{T}^{\prime}{ }_{\mathrm{DS}}$ \\
\hline 10 & 7.92 & 8.73 & 13.6 & 7.9 \\
\hline 20 & 9.20 & 11.09 & 27.4 & 15.7 \\
\hline 50 & 10.78 & 14.24 & 68.9 & 39.3 \\
\hline 100 & 11.90 & 16.63 & 137.9 & 78.4 \\
\hline 200 & 12.98 & 19.04 & 276.1 & 156.8 \\
\hline 500 & 14.34 & 22.23 & 690.7 & 391.8
\end{tabular}

Figures 


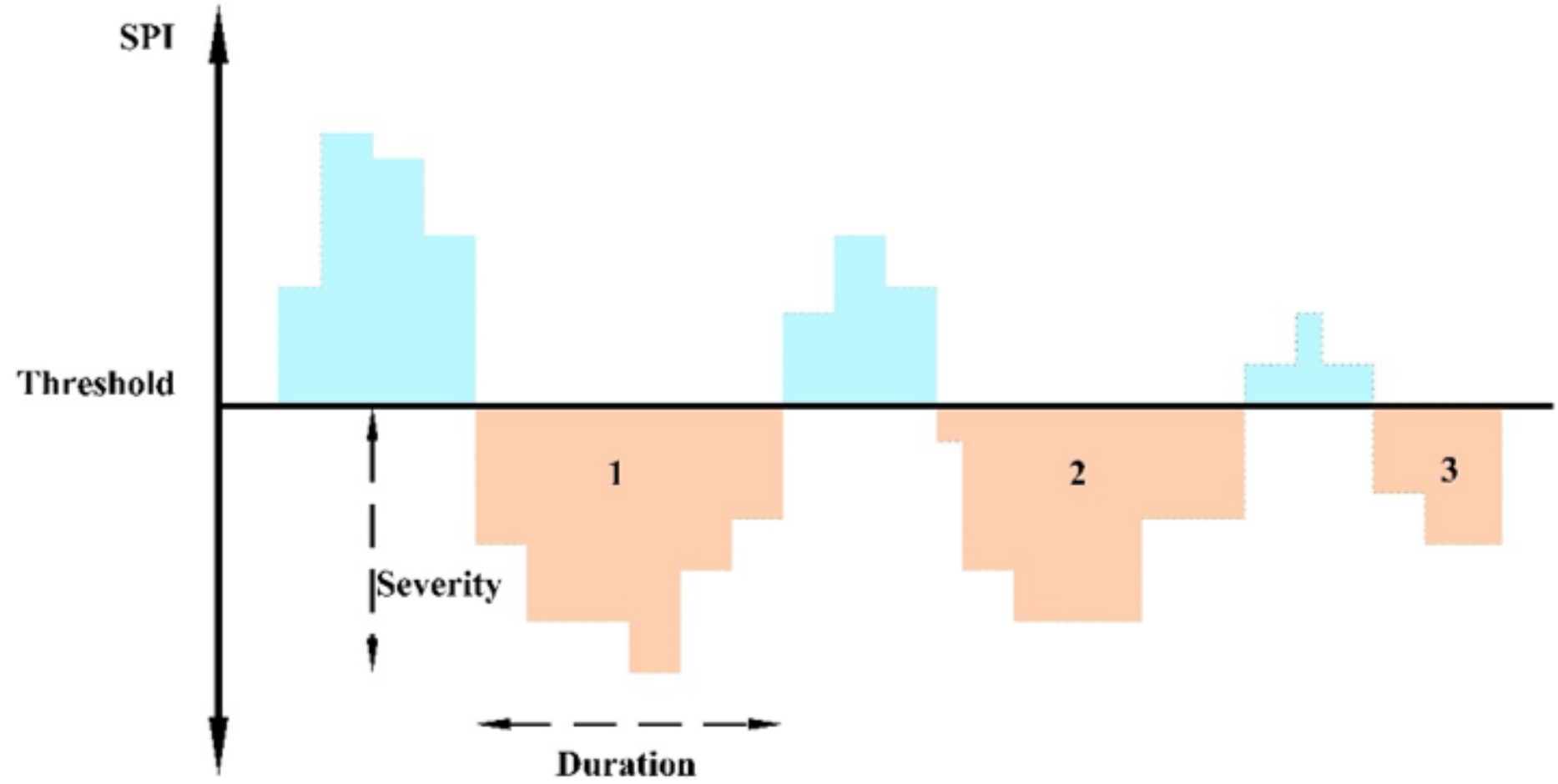

Figure 1

The definition of drought characteristics 

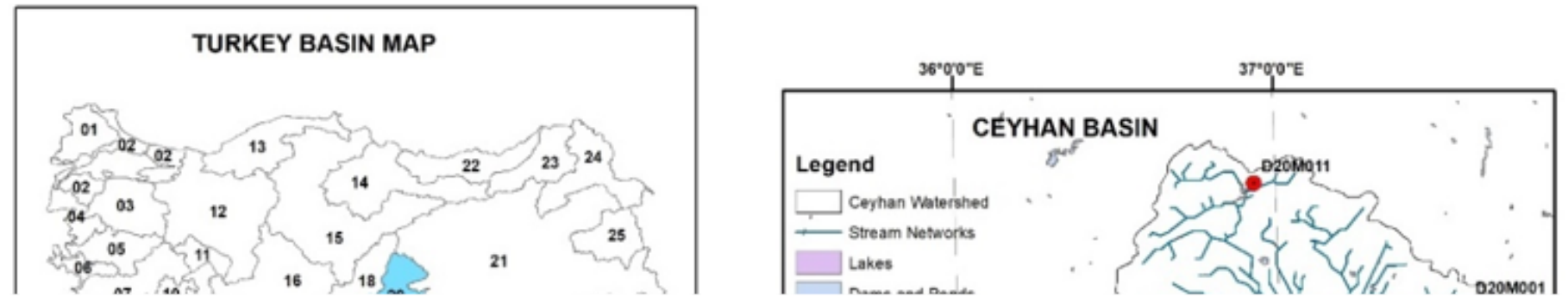

Figure 2

The location of the meteorological stations in the Ceyhan Basin 


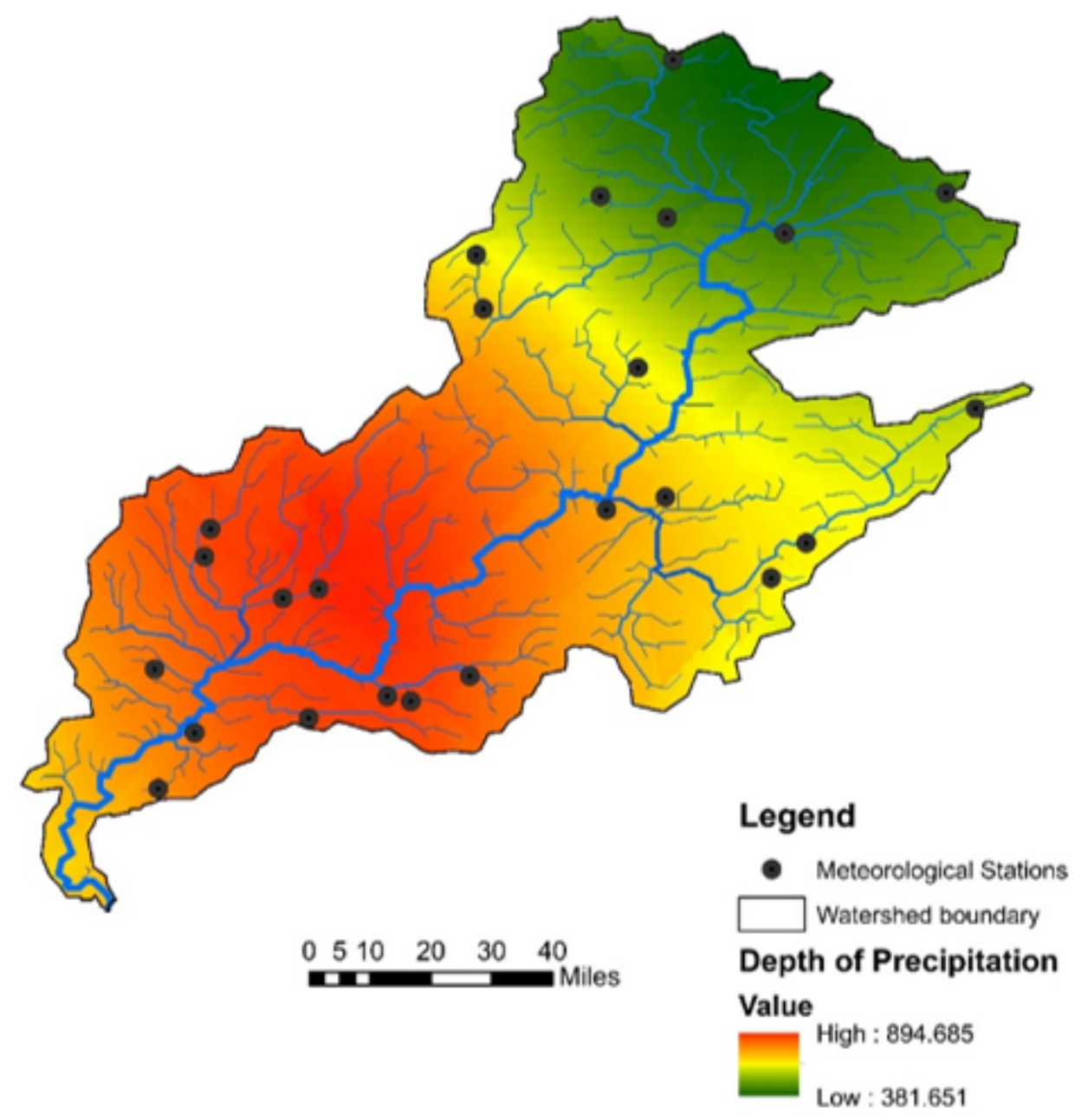

Figure 3

Annual depth of precipitation distribution in Ceyhan basin 


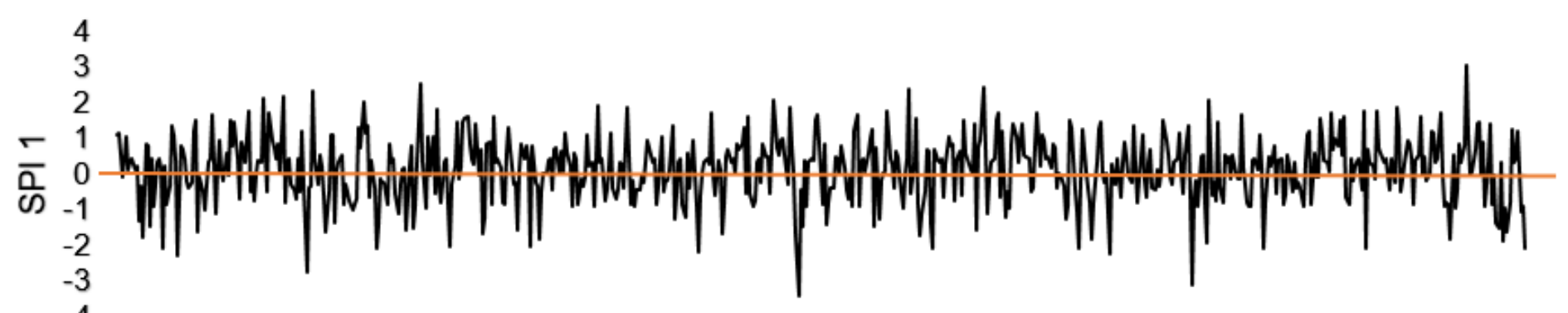

$-4$

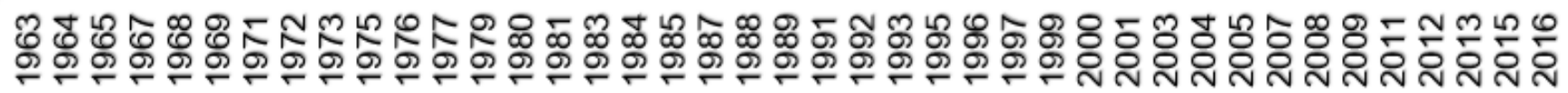
Year
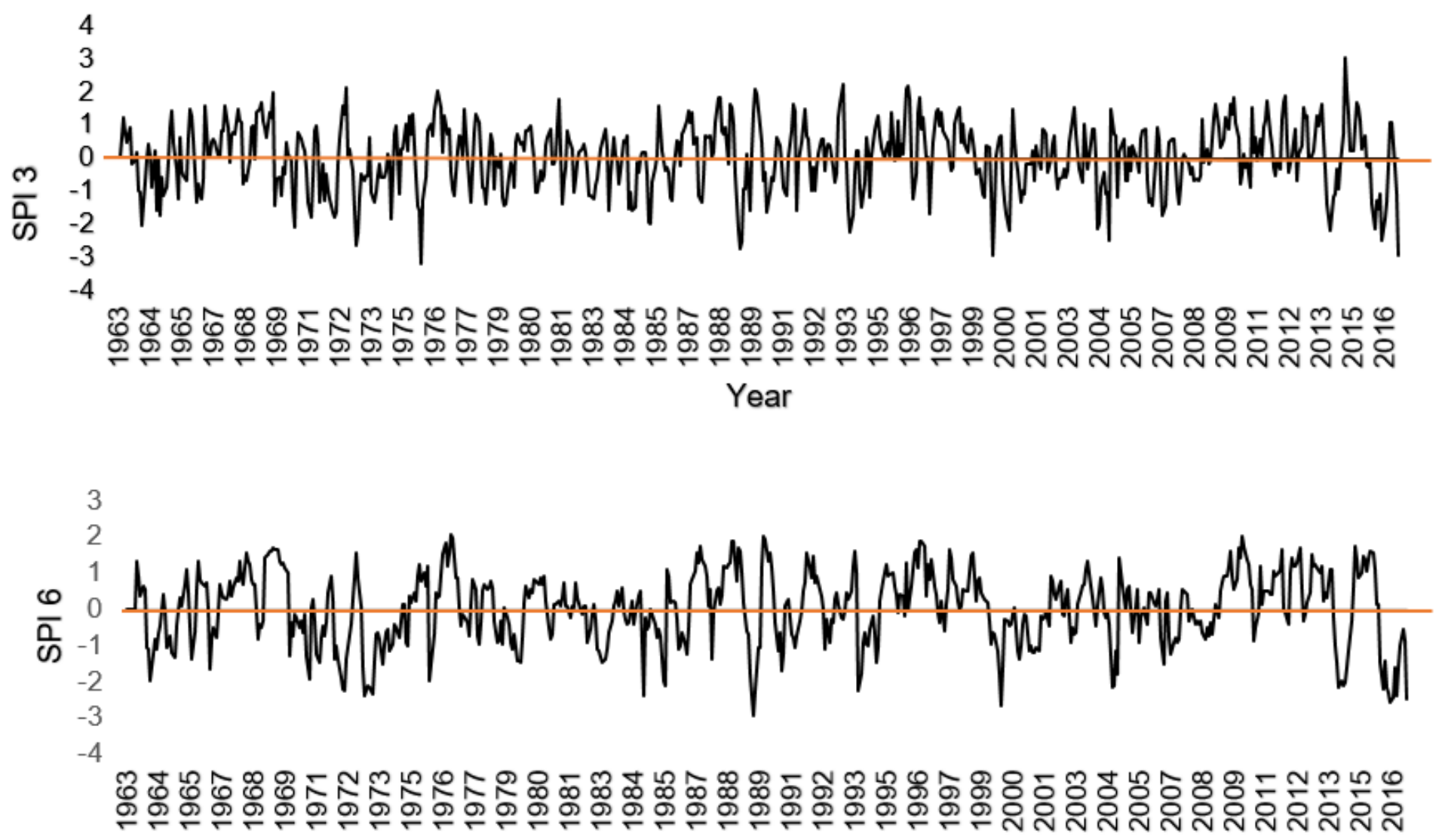

Year

Figure 4

An example of SPI index for the precipitation data plotted for the time scale of 3 month (station 17255) 


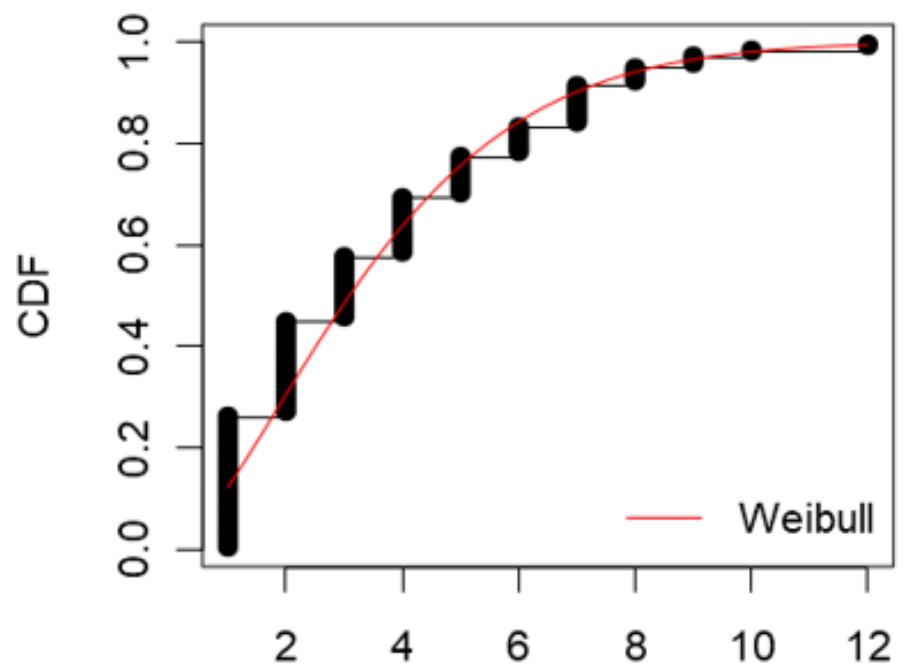

data
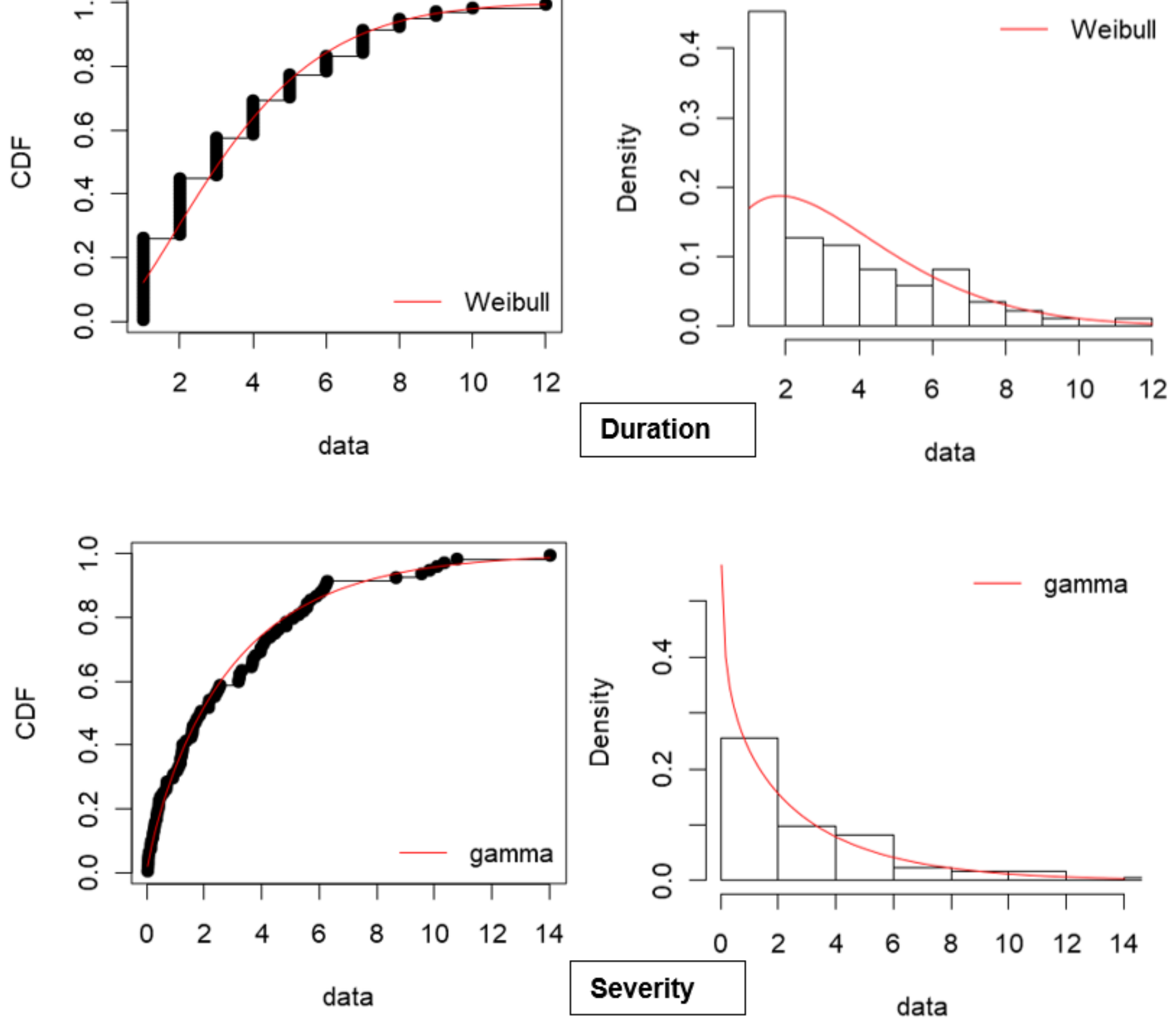

Figure 5

Cumulative distribution function (CDF) and Probability density function (PDF) of drought duration; CDF and PDF of drought severity (17255 SPI3) for selecting the best fit marginal distribution 


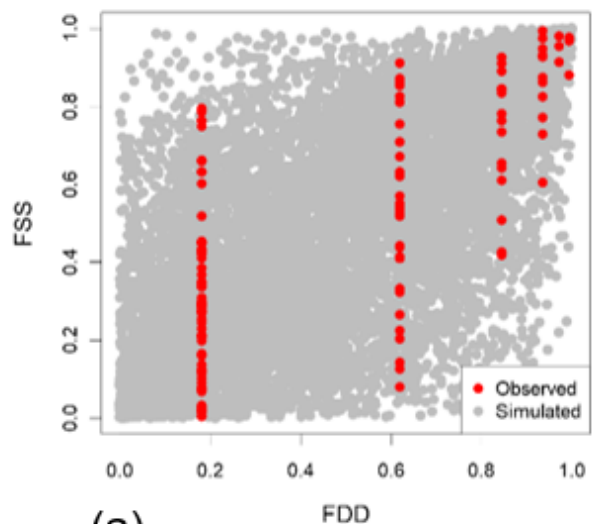

(a)

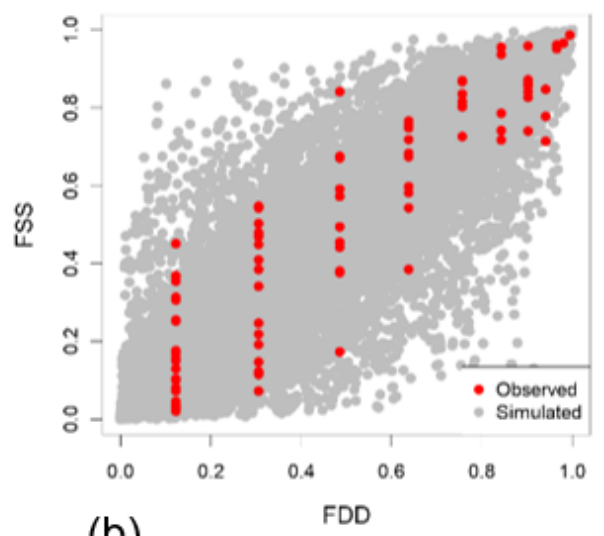

(b)

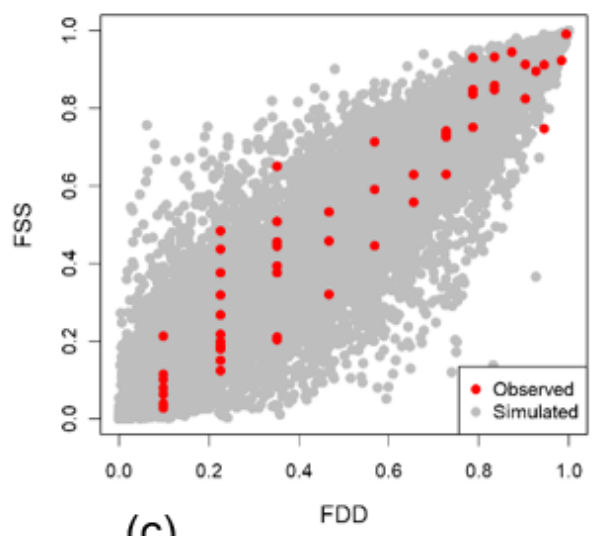

(c)

Figure 6

Comparison of simulated random data (grey data) and observed data (red data) using (a) fitted Gumbel copula for SPI1, (b) fitted BB1 copula for SPI3 and (c) fitted Gumbel copula for SPI6 (station 17255; FDD and FSS are $u_{1}$ (CDF; drought duration, $v_{1}$ (CDF; drought severity, respectively)

\section{Figure 7}

The joint return period of drought duration and severity ((a)-SPI1, (b)-SPI3 and (c)-SPI6) in two cases; $T_{D S}$ (left) and $T_{D S}^{\prime}$ (right) (station 17255)

\section{Figure 8}

The spatial distribution of $T_{D S}$ (left) and $T_{D S}^{\prime}$ (right) return period (month) based on SPI1 when the drought duration and severity exceed their long-term average 

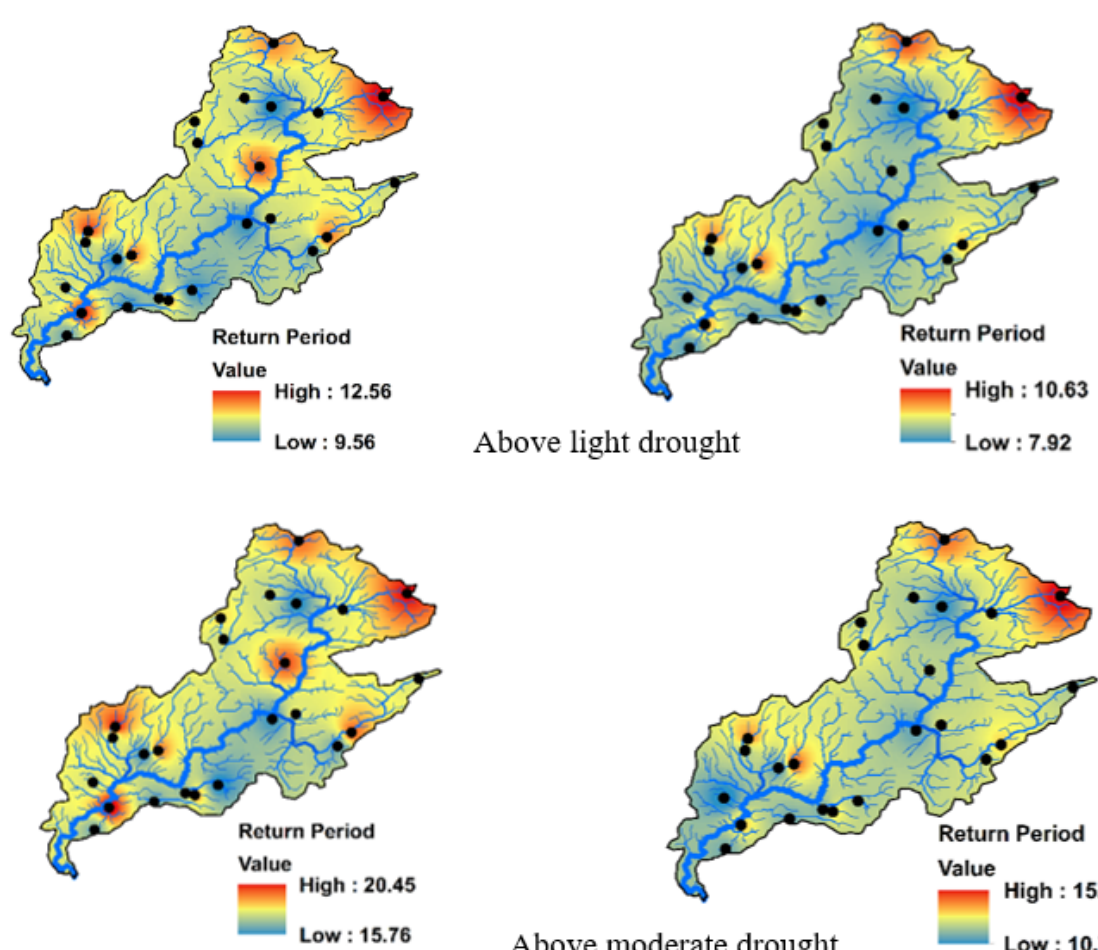

Above light drought

Value
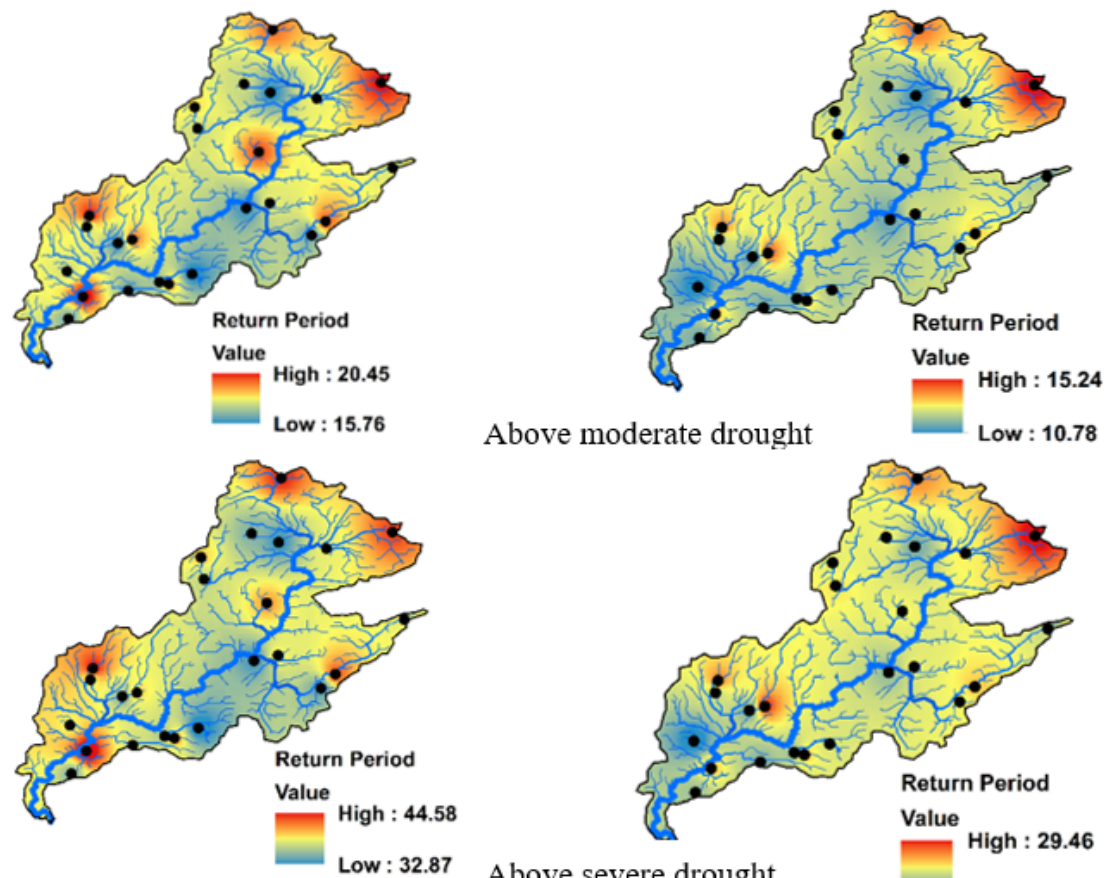

Above moderate drought

Low : 10.78

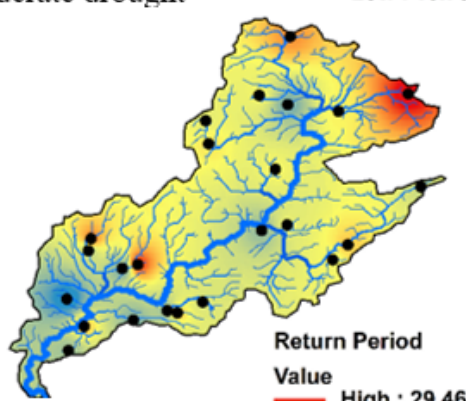

Above severe drought
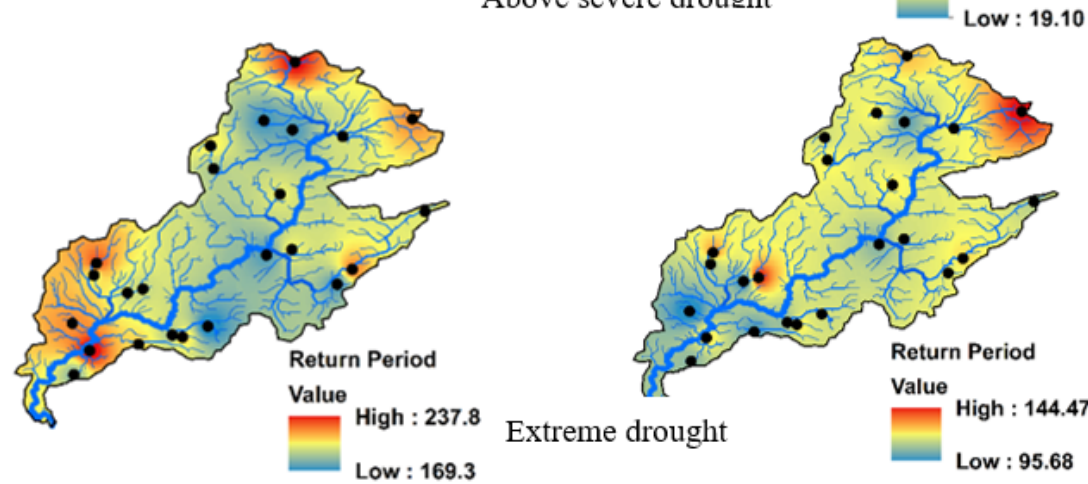

\section{Figure 9}

The spatial distribution of $T_{D S}$ (left) and $T_{D S}^{\prime}$ (right) return period (month) based on SPI3 when the drought duration and severity exceed their long-term average 


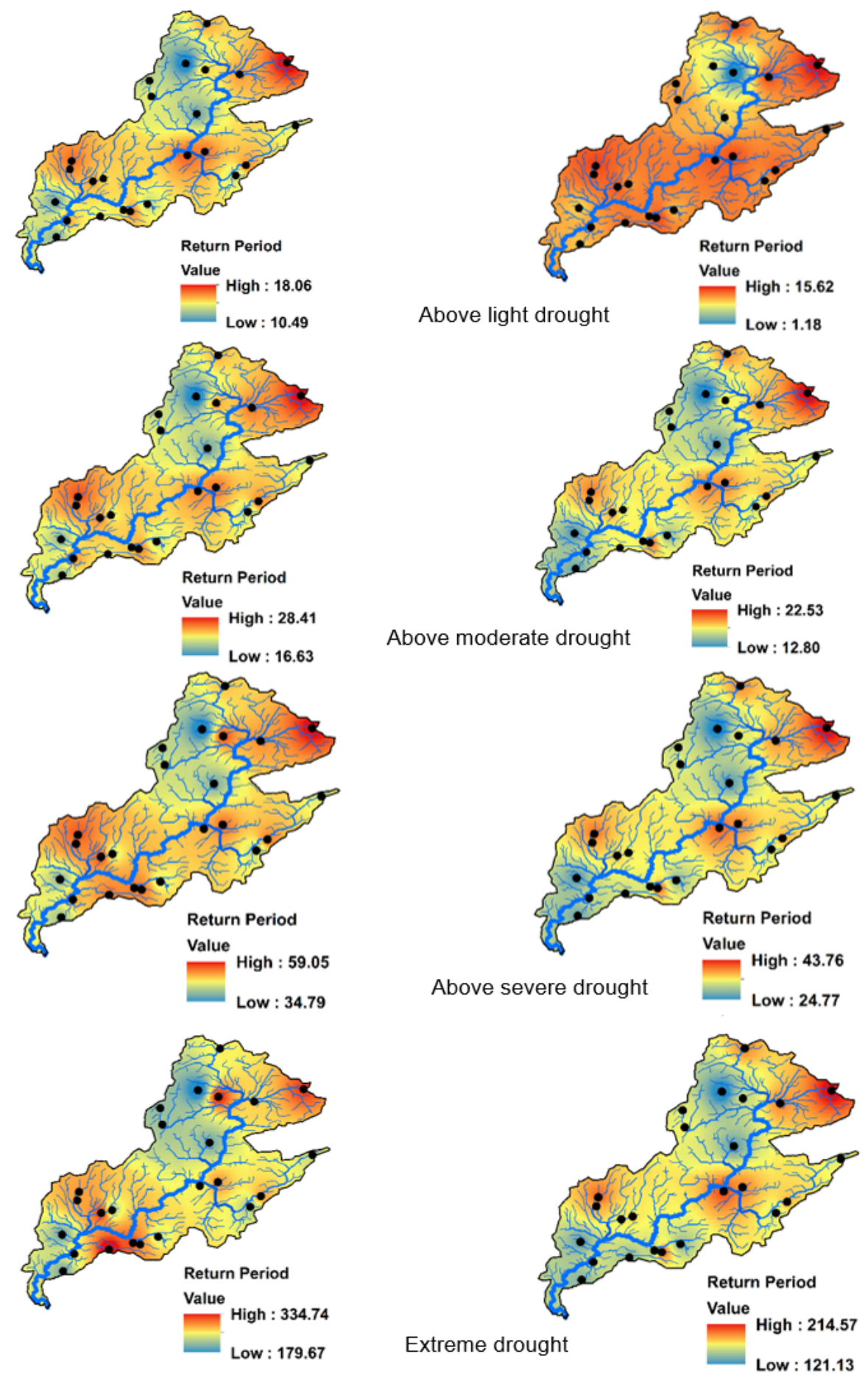

\section{Figure 10}

The spatial distribution of $T_{D S}$ (left) and $T_{D S}^{\prime}$ (right) return period (month) based on SPI6 when the drought duration and severity exceed their long-term average

\section{Supplementary Files}


This is a list of supplementary files associated with this preprint. Click to download.

- Table23.docx 